OPEN ACCESS

Edited by:

Youji Wang

Shanghai Ocean University, China

Reviewed by:

Tiziano Verri,

University of Salento, Italy

Alejandro S. Mechaly,

Consejo Nacional de Investigaciones Cientificas y Técnicas (CONICET),

Argentina

Richard Londraville,

University of Akron, United States

Lorenzo Gallus,

Università di Genova, Italy

*Correspondence: Jie Mei

jmei@mail.hzau.edu.cn

${ }^{\dagger}$ These authors have contributed equally to this work.

Specialty section:

This article was submitted to

Aquatic Physiology,

a section of the journal

Frontiers in Physiology

Received: 22 August 2017 Accepted: 14 November 2017 Published: 30 November 2017

Citation:

Zhang J, Ma W, He Y, Dawar FU, Xiong S and Mei J (2017) Potential Contributions of miR-200a/-200b and

Their Target Gene-Leptin to the

Sexual Size Dimorphism in Yellow

Catfish. Front. Physiol. 8:970.

doi: 10.3389/fphys.2017.00970

\section{Potential Contributions of miR-200a/-200b and Their Target Gene-Leptin to the Sexual Size Dimorphism in Yellow Catfish}

\author{
Jin Zhang ${ }^{1 \dagger}$, Wenge $\mathrm{Ma}^{1+}$, Yan $\mathrm{He}^{1}$, Farman U. Dawar ${ }^{1,2}$, Shuting Xiong ${ }^{1}$ and Jie Mei ${ }^{{ }^{*}}$ \\ ${ }^{1}$ Key Laboratory of Freshwater Animal Breeding, College of Fisheries, Ministry of Agriculture, Huazhong Agricultural \\ University, Wuhan, China, ${ }^{2}$ Department of Zoology, Kohat University of Science and Technology, Kohat, Pakistan
}

Sexual size dimorphism is the consequence of differential expression of sex-biased genes related to feeding and growth. Leptin is known to regulate energy balance by regulating food intake. In order to investigate the molecular mechanism of sexual size dimorphism in yellow catfish (Pelteobagrus fulvidraco), the expression of leptin (lep) and its functional receptor (lepr) were detected during larval development. Both lep and lepr have lower expression in males than in females during 1-4 weeks post hatching. 17a-Methyltestosterone (MT) treatment resulted in decreased expression of lep and lepr in both male and female larval fish. Interestingly, the mRNA levels of lep and lepr in juvenile male were significantly decreased compared with juvenile female during short-term fasting periods. Lep was predicted to be a potential target of miR-200a and miR-200b that had an opposite expression pattern to lep in male and female larvas. The results of luciferase reporter assay suggested that lep is a target of miR-200a/-200b. Subsequently, male hormone and fasting treatment have opposite effects on the expression of miR-200a/-200b and lep between males and females. In summary, our results suggest that sexual size dimorphism in fish species is probably caused by the sexually dimorphic expression of leptin, which could be negatively regulated by miR-200a/-200b.

Keywords: miR-200a/b, leptin, sexual dimorphism, fasting, sex hormone

\section{INTRODUCTION}

Sexual size dimorphism is a systematic difference in size, shape, color, physiology and behavior between male and female individuals of the same species in vertebrates. The sexual size dimorphism that is due to different growth rate between male and female individuals has been found in many cultivated fish species, such as tilapia (Oreochromis niloticus) (Beardmore et al., 2001), rainbow trout (Oncorhynchus mykiss) (Bye and Lincoln, 1986) and yellow catfish (Pelteobagrus fulvidraco) (Gui and Zhu, 2012; Mei and Gui, 2015). Although, studies have been conducted to elucidate the sexual size dimorphism in fish, the exact molecular mechanism underlying is still unclear (Mei and Gui, 2015).

Growth hormone (GH)/insulin-like growth factor (IGF) is crucial in regulating somatic growth in vertebrates (Duan, 1998; Perez-Sanchez and LeBail, 1999; Reinecke, 2006). Ghrelin is a potent stimulator of growth hormone $(\mathrm{GH})$ from pituitary and has been recognized to promote food 
intake and body weight gain (Tschöp et al., 2000; Nakazato et al., 2001). As an anorexigenic peptide hormone, Leptin circulates to maintain energy homeostasis by balancing feeding and energy expenditure in the body of vertebrates (Ahima and Flier, 2000; Arora, 2008). Moreover, Leptin could regulate GHR and IGFs expression to coordinate somatic growth with nutritional state (Won et al., 2016).

The miRNAs are small non-coding RNA molecules that play predominantly inhibitory regulatory roles to gene expression by binding to the $3^{\prime}$ untranslated region ( $3^{\prime} \mathrm{UTR}$ ) of target mRNAs (Bartel, 2004; Derghal et al., 2017). MiR-200 family is highly conserved in vertebrates, including miR$200 a / 200 b / 200 c / 429 a / 429 b / 141$, which are widely expressed in many tissues, such as pituitary gland, testes, prostate gland, ovary, breast, and liver (Landgraf et al., 2007). It is widely known as an inhibitor of the epithelial-to-mesenchymal transition and tumor suppressor (Griffiths-Jones et al., 2006; Becker et al., 2015; Trümbach and Prakash, 2015). In zebrafish, miR-200 family members have been shown to control body size by reducing the expression of GH, GHRa, GHRb, IGF1, and IGF2a during embryo development (Jing et al., 2015). Research in mice suggested that miR-200a was involved in the regulation of leptin and insulin expression in the hypothalamus (Crépin et al., 2014; Derghal et al., 2017).

Yellow catfish is a distinctive species for sexual size dimorphism, in which males grow much faster than females. Some reports find that sexually dimorphic expression genes were identificated in yellow catfish transcriptome (Lu et al., 2014, 2015; Wu et al., 2015). Our previous study demonstrated that sex differences in the expression of GH/IGF signaling genes and ghrelin/GHSR might be involved in the sexual size dimorphism in yellow catfish. The sex hormones, 17-Alpha-methyltestosterone (MT) and 17-alpha-ethinyl estradiol (EE2) could alter expression of these genes related to body growth (Ma et al., 2016; Zhang et al., 2016). In this study, we investigated expression changes of miR-200a/-200b and their target gene leptin during larval development, under the effects of fasting and sex hormone treatment. Our results demonstrate potential contributions of miR-200a/-200b and their target gene leptin to the sexual size dimorphism in yellow catfish.

\section{MATERIALS AND METHODS}

\section{Animals and Samples}

Ten male and ten female two-year-old sexually mature yellow catfish were obtained for artificial fertilization from our breeding center at Huazhong Agricultural University, China. Different stages of larval and juvenile fish were treated and sampled in accordance with the guiding principles approved by the institution animal care and use committee of Huazhong Agricultural University (Ethical Approval No. HBAC20091138; Date: 15 November 2009).

To investigate the effects of fasting on gene expression, shortterm fasting experiments were designed. As mentioned in our previous reports (Zhang et al., 2016), yellow catfish were cultured in six glass tanks and in $25-26^{\circ} \mathrm{C}$ aerated water with a natural photoperiod in standard $24 \mathrm{hr}$ time clock. In brief, all fish were fed at 8:00 and 16:00 using commercial blood worm for 2 weeks. A group of juvenile fish was fasted, while others were fed as above. Fifteen fish (five from each group) were randomly collected on specific time period $(8: 00,8: 30,9: 30,11: 00,14: 00)$. The fish was sampled at 8:00 a.m. to detect gene expression prior to normal feeding time.

To evaluate the effects of sex hormone on gene expression, 4-day-old larvae (size: $4 \pm 0.3 \mathrm{~mm}$ ) were randomly selected after artificial fertilization. The fish were separately cultured in two groups and maintained at $25-26^{\circ} \mathrm{C}$. One group was fed thrice a day with filtered artemia that was firstly soaked in $100 \mu \mathrm{g} / \mathrm{L} 17 \mathrm{a}-$ methyltestosterone (MT) for $1 \mathrm{~h}$. The control group was fed with filtered artemia without MT treatment. Samples were collected weekly for 4 weeks. The whole fish (larvae and juveniles) were sampled in all experiments because the fish were too small to collect the specific tissues. The tail of each fish was cut down for sex identification using sex-linked markers as previously described (Dan et al., 2013), and the rest of the fish (head and trunk) was frozen in liquid nitrogen and stored at $-80^{\circ} \mathrm{C}$ until RNA extraction. The experimental condition and method were the same as two previous studies (Ma et al., 2016; Zhang et al., 2016).

\section{Total RNA Extraction and cDNA Synthesis}

The extraction of total RNAs from yellow catfish samples was conducted by TRIzol (Invitrogen, USA) according to the manufacturer's instruction. Each sample was collected from 5 individuals. RNA quality and quantity were determined by A260 measurement (NANODROP2000, Thermo). RNA integrity was assessed by electrophoresis. RNA was diluted to $200 \mathrm{ng} / \mu \mathrm{L}$ with RNase-free deionized water. Subsequently, the total RNA was reverse transcribed into $\mathrm{cDNA}$ using PrimeScript ${ }^{\mathrm{TM}} \mathrm{RT}$ reagent Kit with gDNA Eraser (Stratagene, Takara).

\section{Quantitative Analysis of Gene Expression by qRT-PCR}

The expression levels of genes were examined using quantitative fluorescent RT-PCR (Bio-rad, USA). The qRT-PCR was accomplished using $\beta$-actin as the internal control. Primers were designed by Primer Premier 5.0 software and listed in Table 1. The protocol of qRT-PCR and analysis method were used as described, and the relative expression of each gene was analyzed using $2^{-\Delta \Delta \mathrm{Ct}}$ method (Zhang et al., 2016). The 20 $\mu \mathrm{L}$ reaction cocktail included $10 \mu \mathrm{L} 2 \times$ SYBR green master mix (Bio-rad, USA), $0.5 \mu \mathrm{L}(10 \mu \mathrm{M})$ of each primers (forward and reverse), $2 \mu \mathrm{L}$ cDNA template and $7 \mu \mathrm{L}$ double distilled water. The reaction conditions were as follows: $95^{\circ} \mathrm{C}$ for $30 \mathrm{~s}$ followed by 40 cycles at $95^{\circ} \mathrm{C}$ for $10 \mathrm{~s}, 58^{\circ} \mathrm{C}$ for $10 \mathrm{~s}$ and $72^{\circ} \mathrm{C}$ for $15 \mathrm{~s}$ and concluding with a single elongation step at $72^{\circ} \mathrm{C}$ for $5 \mathrm{~min}$ (Bio-rad, USA). Melt curve analysis was performed to verify single product generation at the end of the assay. The amplification efficiencies were $1.09,0.82,0.98,1.01,1.02,1.03$ for lep, lepr, $\beta$-actin, miR-200a, miR-200b, and $5.8 s$ that were calculated according to a previous description (Sinha et al., 2015). Amplicons were verified by sequencing (TSINGKE, Beijing). All experiments and measurements were performed in triplicate. 


\section{Cell Transfection and Luciferase Reporter Assay}

3'UTR fragments of leptin gene, which contains one putative miR-200a/-200b binding site was inserted into the pmirGLO plasmid (Promega). Then, the binding site of miR-200a (AGTGTT) in the constructed wild-type plasmid was replaced with GACACG by site-directed mutagenesis (Mei et al., 2011). MUT represented the mutation of predicted binding site of miR$200 \mathrm{a} /-200 \mathrm{~b}$ in leptin gene. Hela cells were transiently transfected with plasmid of wild-type (25 ng) or mutant (25 $\mathrm{ng}$ ) and miRNA mimics $(50 \mathrm{nM})$ or negative control $(50 \mathrm{nM})$ per 24 -well using DharmaFECT transfection reagent (Dharmacon). Twentyfour hours post transfection, luciferase activity was measured using Dual Luciferase reporter assay system (Promega). Relative reporter activities were determined by normalizing Firefly activity to Renilla activity.

TABLE 1 | The primers for QRT-PCR.

\begin{tabular}{|c|c|c|c|c|}
\hline Primers & Sequences $\left(5^{\prime}-3^{\prime}\right)$ & Applications & $\begin{array}{l}\text { Size of the } \\
\text { products } \\
\text { (bp) }\end{array}$ & $\begin{array}{l}\text { Genbank } \\
\text { Accession }\end{array}$ \\
\hline Leptin-F & ACTTCCAGCGAGTCCTTC & qPCR & 209 & JQ288727 \\
\hline Leptin-R & CAGTCTGTCCAGAGCCAC & qPCR & 209 & \\
\hline $\begin{array}{l}\text { Leptin } \\
\text { receptor-F }\end{array}$ & AGCCAATCAGAGCCTTAG & qPCR & 160 & $J X 118825$ \\
\hline $\begin{array}{l}\text { Leptin } \\
\text { receptor-R }\end{array}$ & TACATTCGCTTGTTCGTC & qPCR & 160 & \\
\hline miR-200a-F & GCGCTAACACTGTCTGGTAA & qPCR & 71 & MG383687 \\
\hline miR-200a-R & GTGCAGGGTCCGAGGT & qPCR & 71 & \\
\hline miR-200b-F & GCGCTAATACTGCCTGGTAA & qPCR & 73 & MG383688 \\
\hline miR-200b-R & GTGCAGGGTCCGAGGT & qPCR & 73 & \\
\hline$\beta$-actin-F & TCCCTGTATGCCTCTGGTCGT & qPCR & 179 & EU161065 \\
\hline$\beta$-actin-R & AAGCTGTAGCCTCTCTCGGTC & qPCR & 179 & \\
\hline $5.8 \mathrm{~s}-\mathrm{F}$ & TCTTAGCGGTGGATCACTCG & qPCR & 51 & GQ376028 \\
\hline $5.8 s-R$ & AGCTGGCTGCGTTCTTCAT & qPCR & 51 & \\
\hline
\end{tabular}

\section{Statistical Analysis}

Each result and figure was from three independent experiments as biological replicates. Data are represented as the mean \pm SEM from three independent experiments. Differences in dependent variables were analyzed in a two-way ANOVA according to general linear modeling using treatment and time as fixed factors. Data was tested for homoscedasticity and normality. A probability $(P<0.05)$ was considered statistically significant. ${ }^{*} P<0.05,{ }^{* *} P<0.01$, and ${ }^{* * *} P<0.001$.

\section{RESULTS}

\section{Expression of Leptin, Leptin Receptor and miR-200a/-200b during Larval Development}

QRT-PCR was performed to detect the expresson of lep (JQ288727), lepr (JX118825) and miR-200a/-200b during larval development in yellow catfish. Lep was expressed significantly lower in male larvae than in female during the stage of 1-3 weeks post hatching (wph), whereas there was no significant expression difference at $4 \mathrm{wph}$ (Figure 1A). In addition, lepr was expressed significantly lower in male larvae than female during 1-4 wpf (Figure 1B). In contrast, the expression of miR-200a was significantly higher in male larvae than in female during the stage of 2-4 wph, whereas there was no significant expression difference at $1 \mathrm{wph}$ (Figure 2A). The expression of miR-200b was significantly higher in male larvae than in female during 1-4 wph in yellow catfish (Figure 2B).

\section{Lep is a Potential Target of miR-200a/-200b}

A binding site for miR-200a and miR-200b was detected in $3^{\prime}$ UTR of lep, and the seeding sequences of miR-200a and miR-200b are the same (Figure 3A). To determine whether lep is a direct target gene of zebrafish miR-200a/-200b, we performed a luciferase reporter assay by linking the $3^{\prime} \mathrm{UTR}$ of lep to the C-terminus of Firefly luciferase present in pmirGLO vector. PmirGLO/3'-UTR
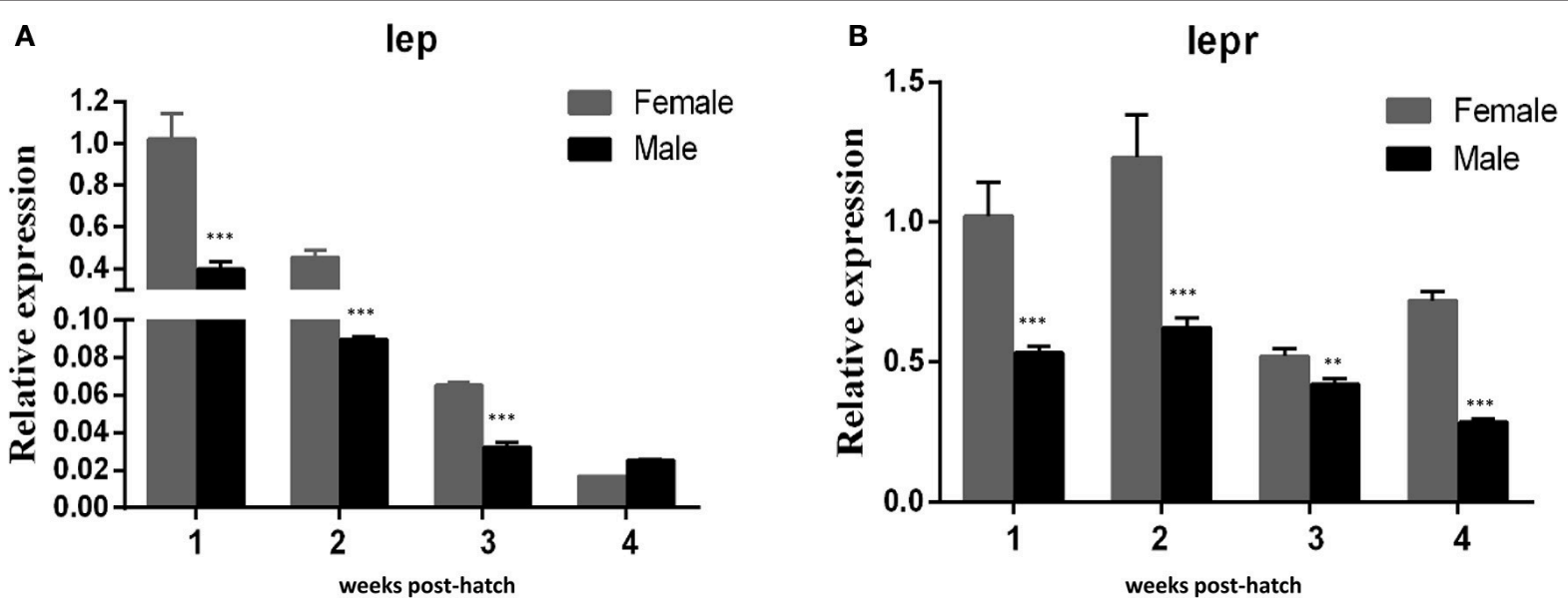

FIGURE 1 | Expression of lep and lepr in juvenile fish among 1-4 weeks post hatching. (A,B) Indicated the relative expression levels of lep and lepr gene during juvenile fish, respectively $\left({ }^{\star \star} P<0.01\right.$ and $\left.{ }^{* \star *} P<0.001\right)$. 

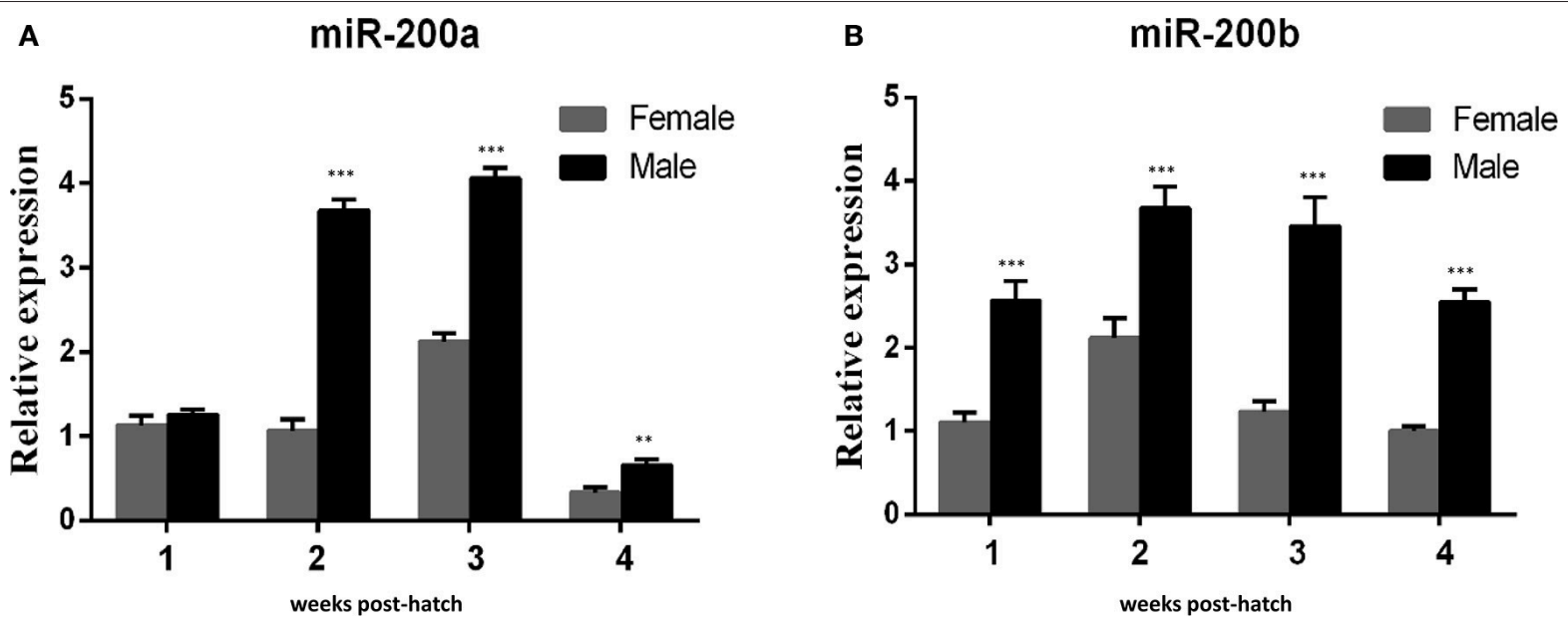

FIGURE 2 | Expression of miR-200a and miR-200b in juvenile fish among 1-4 weeks post hatching. (A,B) indicated the relative expression levels of miR-200a and miR-200b during juvenile fish, respectively ${ }^{\star \star} P<0.01$ and $\left.{ }^{\star \star \star} P<0.001\right)$.

\section{A}

leptin 3'UTR 259 TTCCCAGTGACGTCGCAGTGTTA 281

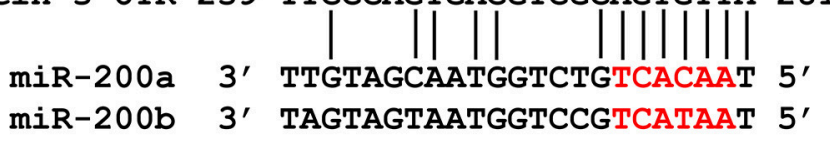

C

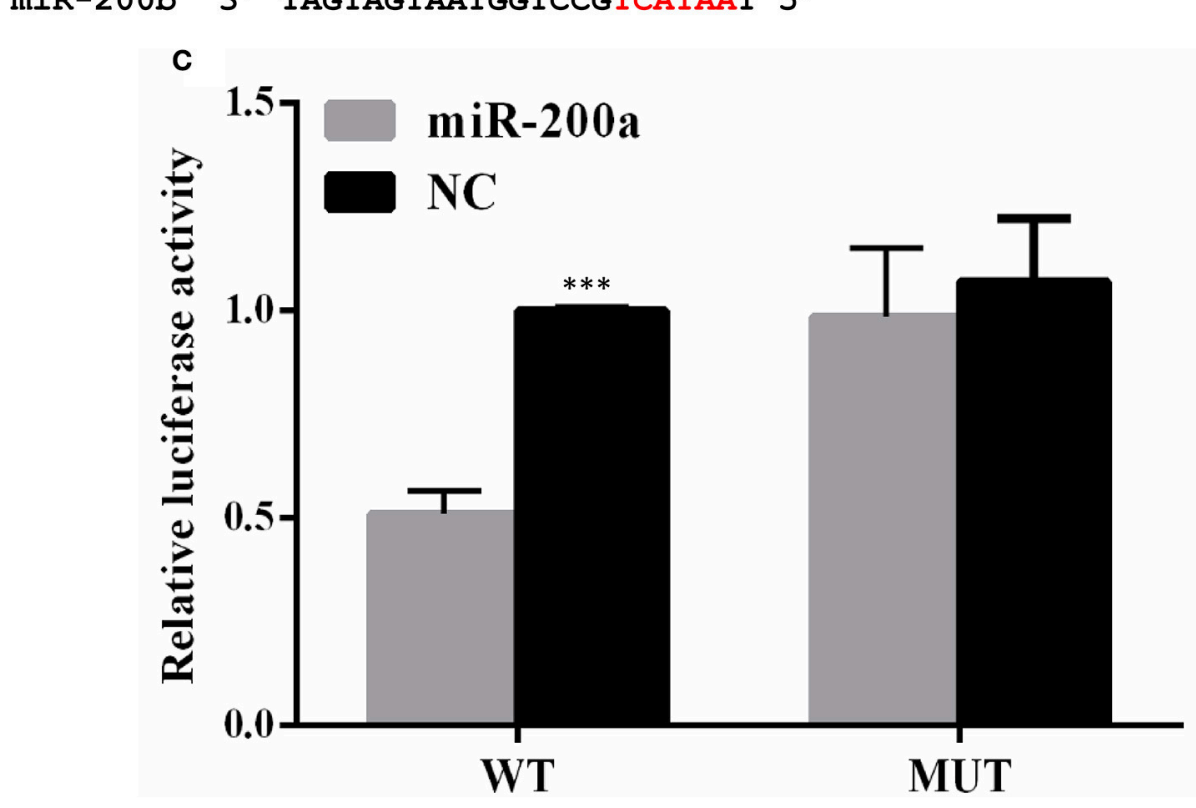

\section{B}

WT : $\quad$ TTCCCAGTGACGTCGCAGTGTTA

MUT: $\quad$ GACACG

FIGURE 3 | Lep is a target of miR-200a. (A) Conserved miR-200a seeding sequence and its binding site in the leptin 3'UTR are marked in red. (B) The sequence information of the putative lep $3^{\prime} U T R$ binding site in wild type (WT) and mutant (MUT) were showed. (C) miR-200a suppressed the activity of pmirGLO-lep $3^{\prime} U T R$ plasmid, but not mutant vector. The Firefly activity was normalized to Renilla expression, which was used as a control for transfection efficiency. Luciferase assays were performed in triplicate and were representative of 3 independent experiments. This experiment was carried on in Hela cell line. NC, negative control. The asterisk indicates the significant differences of gene expression between different groups ( $\left.{ }^{\star \star \star} P<0.001\right)$.

(WT) and its mutant vector (MUT) (Figure 3B) were cotransfected with miR-200a or control microRNA mimic into Hek 293T cells. Luciferase reporter assay showed that miR-200a significantly repressed the luciferase activity of leptin $3^{\prime}$ UTRpmirGLO, whereas mutation in the binding site abrogated this repression (Figure $3 \mathrm{C}$ ). 
Sexually Dimorphic Expression of Lepr and miR-200a/-200b during Fasting

As shown in Figure 4, the expression of lep (Figures 4A,B) and lepr (Figures 4C,D) were significantly decreased in short-term fasting and had very low expression levels at $6 \mathrm{~h}$ post fasting, both in male and female yellow catfish. Compared with the expression in fasted females, the mRNA levels of lep (Figure 4E) and lepr (Figure 4F) were significantly higher in fasted male yellow catfish during $0.5-3 \mathrm{~h}$ fasting. Moreover, the expressions of miR-200a and miR-200b in fasted males were significantly
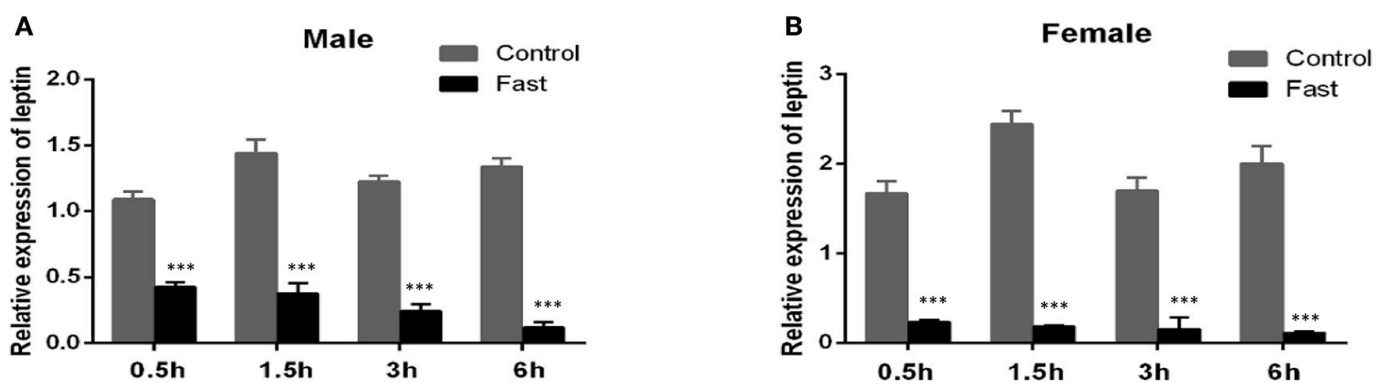

C
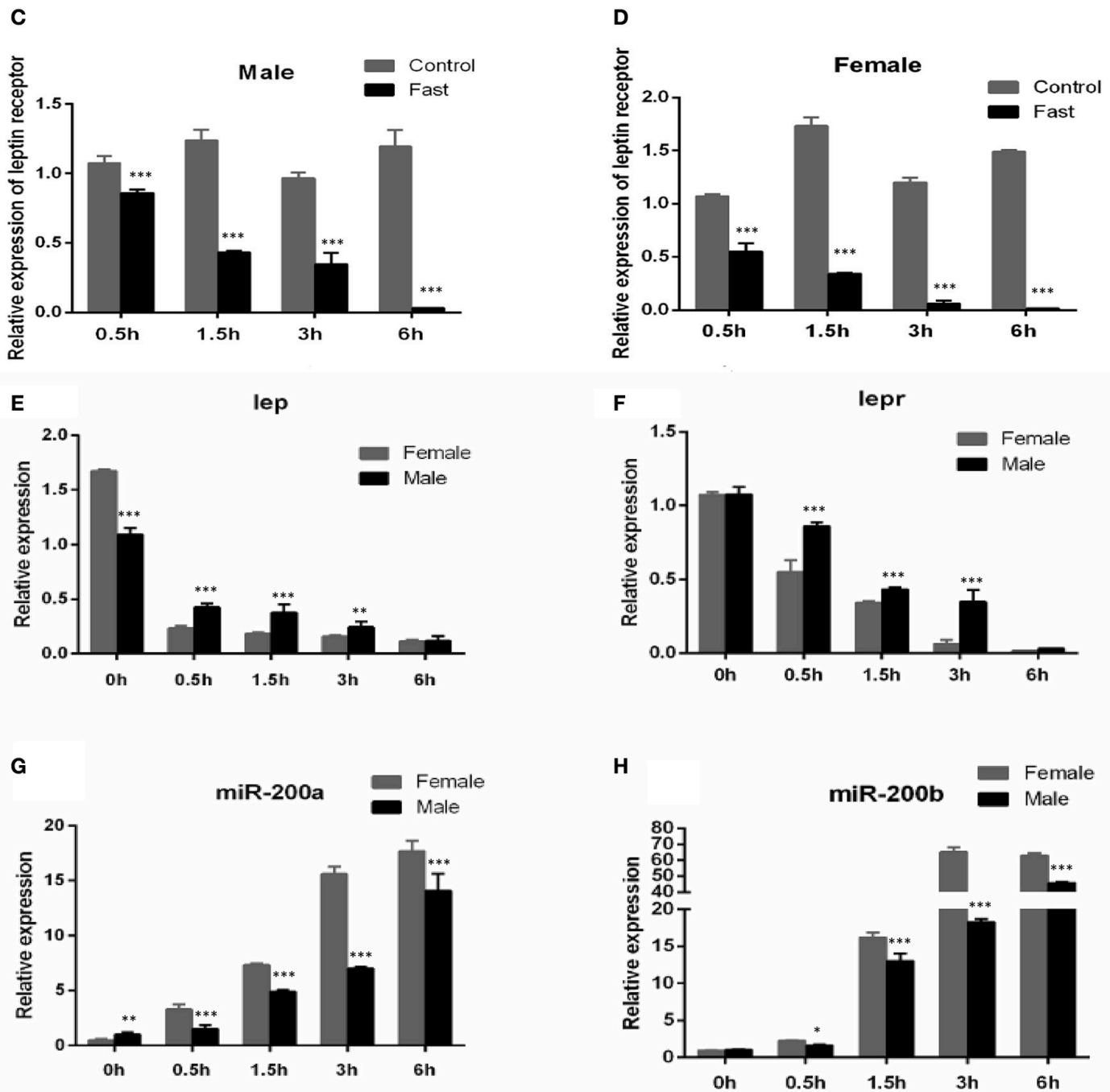

FIGURE 4 | Effects of fasting on the expression of lep, lepr mRNA and miR-200a/b during juvenile growth in yellow catfish. (A-D) showed the effects of short-term fasting on the expression of lep (A,B) and lepr (C,D) mRNA during growth in female and male juvenile yellow catfish respectively. Fast, fasting group; Control, control group. (E-H) showed the effects of short-term fasting on the expression of lep (E), lepr (F), and miR-200a (G) and miR-200b (H) mRNA in male and female juvenile yellow catfish, respectively. The asterisk indicates the significant differences of gene expression between different groups $\left({ }^{\star} P<0.05\right.$, ${ }^{\star \star} P<0.01$, and $\left.{ }^{* \star \star} P<0.001\right)$. 
lower than the expression in fasted females during $0.5-6 \mathrm{~h}$ fasting (Figures 4G,H).

\section{Sexually Dimorphic Expression of Leptin and miR-200 after Hormone Treatment}

Our previous study indicated that sex differences in the expression of ghrelin induced by MT might be involved in the sexual size dimorphism in yellow catfish (Zhang et al., 2016). Ghrelin and leptin play important roles in the regulation of food intake and body weight (Klok et al., 2007). Therefore, the mRNA levels of lep (Figures 5A,B) and lepr (Figures 5C,D) were analyzed and suggested that MT treatment was able to significantly reduce expressions of lep and lepr, both in male and female yellow catfish. Compared with each other, MT treatment resulted in a greater decrease of lep expression in males than in female yellow catfish (Figure 6A). In contrast, we detected a greater increase of miR-200a and miR-200b expression in males than in female yellow catfish after MT treatment (Figures 6B,C).

\section{DISCUSSION}

Sexual difference in growth performance has been observed in many cultivated fish species including yellow catfish, but the molecular mechanism of sexual size dimorphism is still unclear. Several studies have indicated that sexual dimorphism in vertebrates, including fish species are the consequence of sexbiased gene expression and are controlled by multiple critical genes during growth and development (Williams and Carroll, 2009). Our previous studies (Ma et al., 2016; Zhang et al., 2016) have showed that sex difference in the expression of ghrelin and GHSR may be involved in sexual size dimorphism by regulating feeding and GH/IGF signaling in yellow catfish, and both male hormone and fasting could increase the expression of ghrelin (Figure 7). Leptin and Ghrelin are two hormones that have been recognized to play a major role in energy balance. Leptin generally suppresses food intake and thereby inducing weight loss. Ghrelin and GHSR are fast-acting hormones regulating meal initiation. Leptin and Ghrelin stimulate and suppress hypothalamic neurons, resulting in anorexic or orexic effects on energy balance, respectively (Klok et al., 2007). As an antiappetite peptide hormone, Leptin has been proved to regulate growth axis component transcripts and correlated with somatic growth with nutritional state (Won et al., 2012). However, there is no report about the correlation of Leptin with the sexual size dimorphism.

To prevent excessive fat accumulation, Leptin can suppress appetite (Ahima and Flier, 2000). In the present study, leptin expressed much lower in male larvae than in female larvae during 1-3 weeks post hatching (Figure 1), which may explain why male yellow catfish grow much faster than females. In addition, male hormone (MT) could reduce the expression of lep and
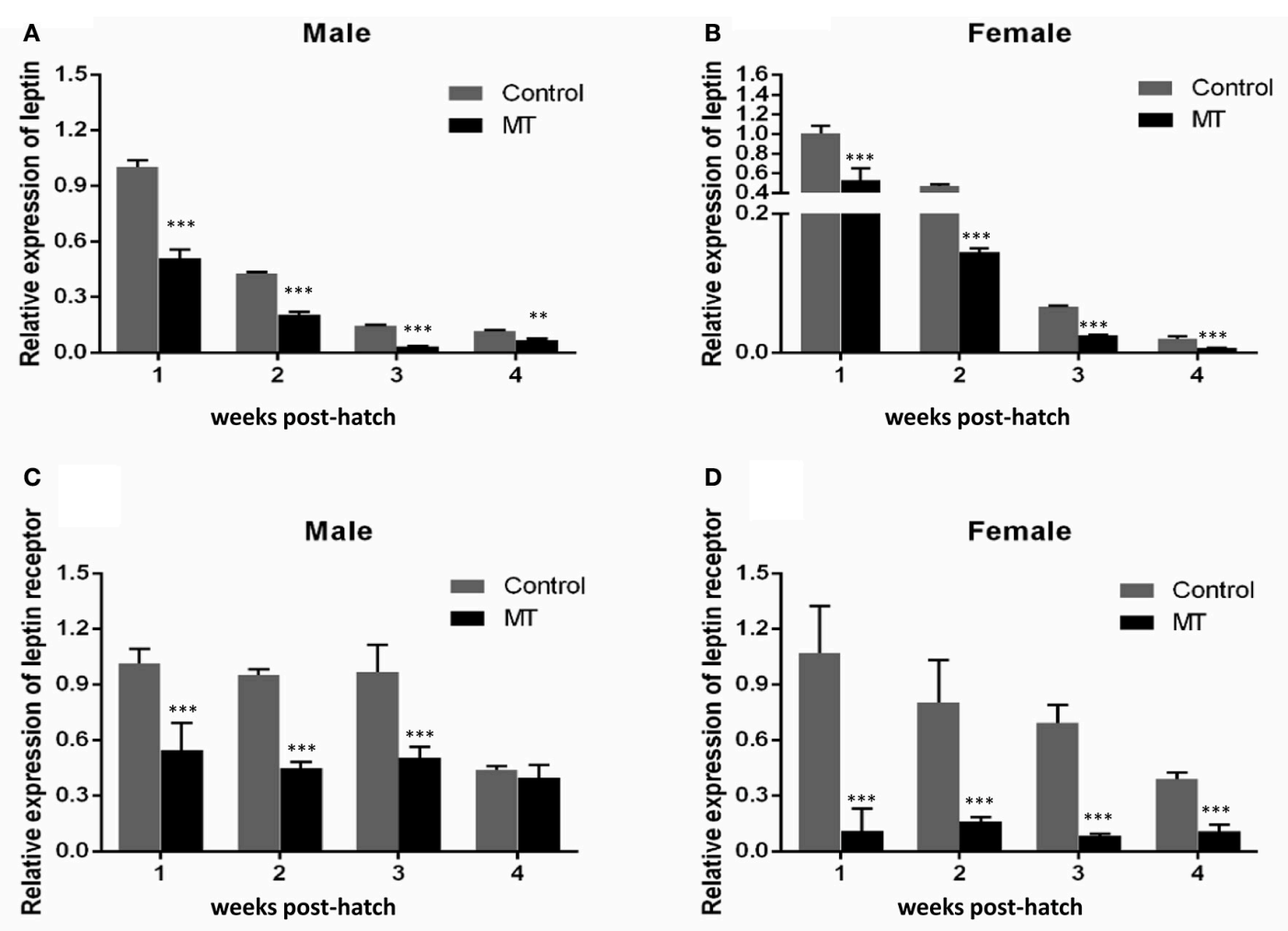

FIGURE 5 | Effects of MT on the expression of lep and lepr mRNA during juvenile growth in male and female yellow catfish. (A-D) showed the expression of lep and lepr mRNA respectively. MT, MT treatment group; Control, control group. The asterisk indicates the significant differences of gene expression between the females and males ${ }^{* \star} P<0.01$ and $\left.{ }^{\star \star \star} P<0.001\right)$. 

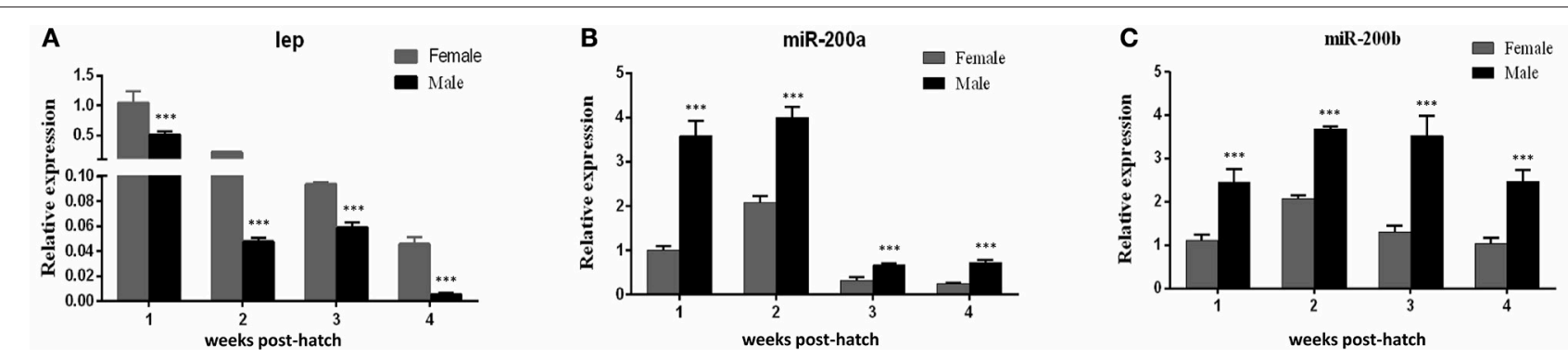

FIGURE 6 | Different effects of MT on the expression of lep and miR200a/b mRNA during juvenile growth between male and female yellow catfish. (A-C) showed the effects of MT on the expression of lep (A) and miR-200a (B) and miR-200b (C) mRNA in male and female juvenile yellow catfish, respectively. The asterisk indicates the significant differences of gene expression between the females and males $\left({ }^{\star \star \star} P<0.001\right)$.

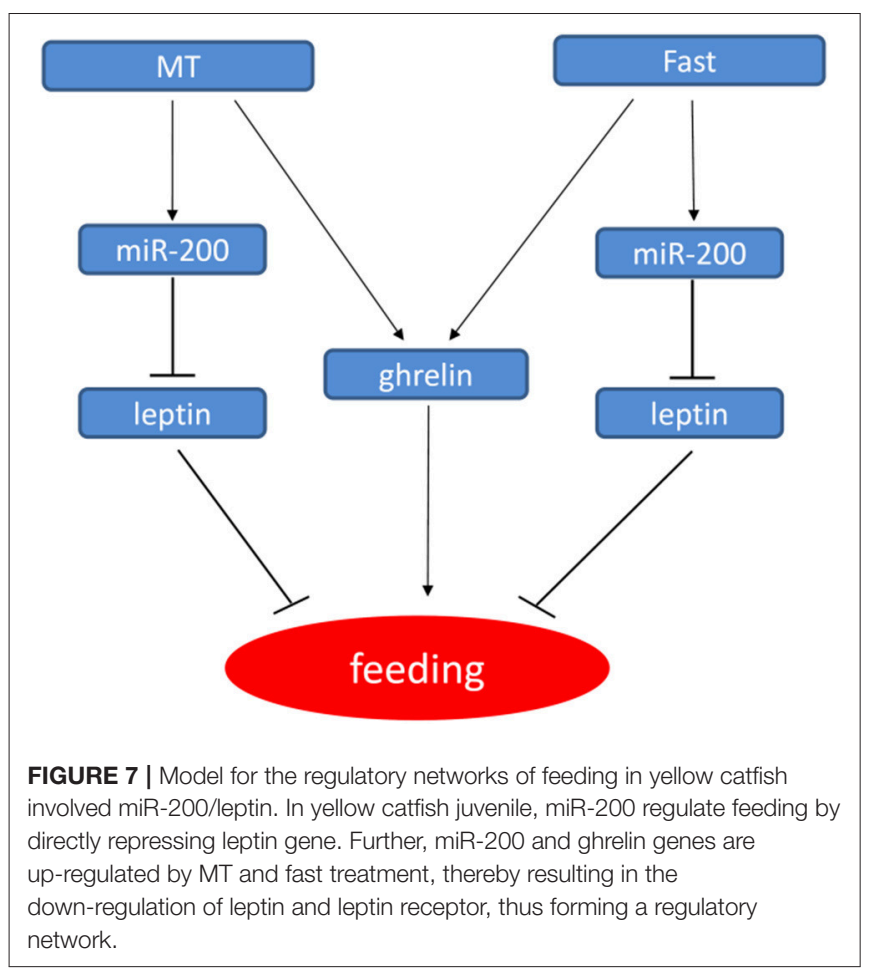

lepr in both male and female larvae (Figure 5). Shen et al. reported that oral administration of $\mathrm{MT}$ at different doses did not significantly change the ratio of males compared to the control group, but produced intersex fish. Their results demonstrated that MT may affect gonadal development and subsequently promot body growth (Shen et al., 2015). Probably, there is a potential interaction between sex and food intake. Leptin can regulate gonadotropic axis, combined with other promoting factors in rainbow trout (Weil et al., 2003). Yellow catfish leptin is expressed in many tissues, such as liver, ovary, mesenteric fat, and spleen (Gong et al., 2013).

The nutritional status is positively correlated with growth performance. In mammals, leptin increases during feeding and promotes satiety and induces lipolysis (Ahima and Flier, 2000). In contrast, leptin decreases during fasting because of the depletion of adipose stores (Harris et al., 1996; Sandoval and Davis, 2003).
Leptin has been cloned in many fish species, such as rainbow trout and salmonid, and it plays important roles in fish somatic growth (Kling et al., 2012; Trombley et al., 2012). In hybrid striped bass, hepatic leptin mRNA expression is sensitive to the nutritional states, declining during fasting catabolic states and increasing under anabolic conditions (Won et al., 2012). Similar to the present study, a recent study indicated that expression of a leptinlike peptide decreases with fasting in green sunfish (Johnson et al., 2000). Administration of exogenous Leptin effectively suppressed the appetite and feeding in goldfish (Volkoff et al., 2003; de Pedro et al., 2006), striped bass (Won et al., 2012), rainbow trout (Murashita et al., 2008), and African clawed frog (Crespi and Denver, 2006). However, different from in mammals, there was no unified correlation between Lep levels and fasting condition in fish species. For example, leptin had an increase trend during fasting in multiple teleosts (Copeland et al., 2011; Gorissen and Flik, 2014), such as in fine flounder, anadromous Arctic charr and rainbow trout (Kling et al., 2009; Fuentes et al., 2012; Jørgensen et al., 2013). In some other studies, fasting was shown to either stimulate leptin or had little effect on leptin expression in goldfish (Volkoff et al., 2003; Tinoco et al., 2012) and striped bass (Huising et al., 2006; Won and Borski, 2013), which might be due to different experimental situations. In our present study, leptin gene expression significantly decreased after fasting both in male and female yellow catfish (Figure 4), suggesting that the adipostatic model for Leptin in mammals may also be applied in yellow catfish.

Mouse miR-200a has been shown to regulate expression of leptin and insulin in the hypothalamus (Crépin et al., 2014; Derghal et al., 2017). In fish species, zebrafish miR-200 family regulate body size by reducing the expression of $G H, G H R a$, GHRb, IGF1, and IGF2a during embryo development (Jing et al., 2015), while rainbow trout miR-200 family members abundantly expressed in the somatic tissues including stomach. And some target genes of miR-141/-200a/-429 were also predicted, which provide a clue to study functions of miR-200 family (Salem et al., 2010). Here, we reported that miR-200a/-200b might play some roles in sexual size dimorphism by targeting lep gene in yellow catfish. Subsequent male hormone treatment and fasting experiments showed that miR-200a/-200b negatively regulate lep gene, and the regulation is different between male and female yellow catfish. We described the model how male hormone 
and fasting stress regulate the expression of ghrelin, miR-200a/b and leptin, and further food intake (Figure 7). The expression of miR200a/-200b was induced after MT treatment to inhibit leptin mRNA level. The decreased leptin level subsequently upregulates feeding signal. In summary, our results suggest that sexual size dimorphism in yellow catfish is partially caused by the sex difference in the expression of lep that could be negatively regulated by $\mathrm{miR}-200 \mathrm{a} /-200 \mathrm{~b}$.

\section{AUTHOR CONTRIBUTIONS}

$\mathrm{JZ}, \mathrm{YH}$, and JM conceived and coordinated the study and wrote the paper. JZ and WM designed, performed and analyzed the

\section{REFERENCES}

Ahima, R. S., and Flier, J. S. (2000). Leptin. Annu. Rev. Physiol. 62, 413-437. doi: 10.1146/annurev.physiol.62.1.413

Arora, S. (2008). Leptin and its metabolic interactions - an update. Diab. Obes. Metab. 10, 973-993. doi: 10.1111/j.1463-1326.2008.00852.x

Bartel, D. P. (2004). MicroRNAs: genomics, biogenesis, mechanism, and function. Cell 116, 281-297. doi: 10.1016/S0092-8674(04)00045-5

Beardmore, J. A., Mair, G. C., and Lewis, R. I. (2001). Monosex male production in finfish as exemplified by tilapia: applications, problems, and prospects. Aquaculture 197, 283-301. doi: 10.1016/S0044-8486(01) 00590-7

Becker, L. E., Takwi, A. A., Lu, Z., and Li, Y. (2015). The role of miR200a in mammalian epithelial cell transformation. Carcinogenesis 36, 2-12. doi: $10.1093 /$ carcin/bgu202

Bye, V. J., and Lincoln, R. F. (1986). Commercial methods for the control of sexual maturation in rainbow trout (Salmo gairdneri R.). Aquaculture 57, 299-309. doi: 10.1016/0044-8486(86)90208-5

Copeland, D. L., Duff, R. J., Liu, Q., Prokop, J., and Londraville, R. L. (2011). Leptin in teleost fishes: an argument for comparative study. Front. Physiol. 2:26. doi: 10.3389/fphys.2011.00026

Crépin, D., Benomar, Y., Riffault, L., Amine, H., Gertler, A., and Taouis, M. (2014). The over-expression of miR-200a in the hypothalamus of ob/ob mice is linked to leptin and insulin signaling impairment. Mol. Cell Endocrinol. 384, 1-11. doi: $10.1016 /$ j.mce.2013.12.016

Crespi, E. J., and Denver, R. J. (2006). Leptin (ob gene) of the south african clawed frog xenopus laevis. Proc. Natl. Acad. Sci. U.S.A. 103, 10092-10097. doi: 10.1073/pnas.0507519103

Dan, C., Mei, J., Wang, D., and Gui, J. F. (2013). Genetic differentiation and efficient sex-specific marker development of a pair of Y-and X-linked markers in yellow catfish. Int. J. Biol. Sci. 9:1043. doi: 10.7150/ijbs.7203

de Pedro, N., Martínez-Alvarez, R., and Delgado, M. J. (2006). Acute and chronic leptin reduces food intake and body weight in goldfish (Carassius auratus). J. Endocrinol. 188, 513-520. doi: 10.1677/joe.1.06349

Derghal, A., Djelloul, M., Trouslard, J., and Mounien, L. (2017). The role of microrna in the modulation of the melanocortinergic system. Front. Neurosci. 11:181. doi: 10.3389/fnins.2017.00181

Duan, C. (1998). Nutritional and developmental regulation of insulin-like growth factors in fish. J. Nutr. 128, 306S-314S.

Fuentes, E. N., Kling, P., Einarsdottir, I. E., Alvarez, M., Valdes, J. A., Molina, A., et al. (2012). Plasma leptin and growth hormone levels in the fine flounder (Paralichthys adspersus) increase gradually during fasting and decline rapidly after refeeding. Gen. Comp. Endocrinol. 177, 120-127. doi: 10.1016/j.ygcen.2012.02.019

Gong, Y., Luo, Z., Zhu, Q. L., Zheng, J. L., Tan, X. Y., Chen, Q. L., et al. (2013). Characterization and tissue distribution of leptin, leptin receptor and leptin receptor overlapping transcript genes in yellow catfish Pelteobagrus fulvidraco. Gen. Comp. Endocrinol. 182, 1-6. doi: 10.1016/j.ygcen.2012. 11.006 experiments shown in Figures. SX and FD provided technical assistance and contributed to the preparation of the figures. All authors reviewed the results and approved the final version of the manuscript.

\section{ACKNOWLEDGMENTS}

This work was supported by the China Agriculture Research System (CARS-46), the Fundamental Research Funds for the Central Universities (52902-0900202949) and the National Natural Science Foundation of China (31672635). The funders had no role in study design, data collection and analysis, decision to publish, or preparation of the manuscript.

Gorissen, M., and Flik, G. (2014). Leptin in teleostean fish, towards the origins of leptin physiology. J. Chem. Neuroanat. 62, 200-206. doi: 10.1016/j.jchemneu.2014.06.005

Griffiths-Jones, S., Grocock, R. J., van Dongen, S., Bateman, A., and Enright, A. J. (2006). miRBase: microRNA sequences, targets and gene nomenclature. Nucleic Acids Res. 34, D140-D144. doi: 10.1093/nar/gkj112

Gui, J. F., and Zhu, Z. Y. (2012). Molecular basis and genetic improvement of economically important traits in aquaculture animals. Chin. Sci. Bull. 57, 1751-1760. doi: 10.1007/s11434-012-5213-0

Harris, R. B., Ramsay, T. G., Smith, S. R., and Brunch, R. C. (1996). Early and late stimulation of ob mRNA expression in meal-fed and overfed rats. J. Clin. Invest. 97, 2020-2026. doi: 10.1172/JCI1 18637

Huising, M. O., Kruiswijk, C. P., and Flik, G. (2006). Phylogeny and evolution of class-I helical cytokines. J. Endocrinol. 189, 1-25. doi: 10.1677/joe.1.06591

Jing, J., Xiong, S., Li, Z., Wu, J., Zhou, L., Gui, J. F., et al. (2015). A feedback regulatory loop involving p53/miR-200 and growth hormone endocrine axis controls embryo size of zebrafish. Sci. Reports 5:15906. doi: 10.1038/srep 15906

Johnson, R. M., Johnson, T. M., and Londraville, R. L. (2000). Evidence for leptin expression in fishes. J. Exp. Zool. 286, 718-724. doi: 10.1002/(SICI)1097-010X(20000601)286:7<718::AID-JEZ6>3.0.CO;2-I

Jørgensen, E. H., Martinsen, M., Strøm, V., Hansen, K. E., Ravuri, C. S., Gong, N., et al. (2013). Long-term fasting in the anadromous Arctic charr is associated with downregulation of metabolic enzyme activity and upregulation of leptin A1 and SOCS expression in the liver. J. Exp. Biol. 216, 3222-3230. doi: $10.1242 /$ jeb.088344

Kling, P., Jönsson, E., Nilsen, T. O., Einarsdottir, I. E., Rønnestad, I., Stefansson, S. O., et al. (2012). The role of growth hormone in growth, lipid homeostasis, energy utilization and partitioning in rainbow trout: interactions with leptin, ghrelin and insulin-like growth factor i. Gen. Comp. Endocrinol. 175, 153-162. doi: 10.1016/j.ygcen.2011.10.014

Kling, P., Ronnestad, I., Stefansson, S. O., Murashita, K., Kurokawa, T., and Bjornsson, B. T. (2009). A homologous salmonid leptin radioimmunoassay indicates elevated plasma leptin levels during fasting of rainbow trout. Gen. Comp. Endocrinol. 162, 307-312. doi: 10.1016/j.ygcen.2009.04.003

Klok, M. D., Jakobsdottir, S., and Drent, M. L. (2007). The role of leptin and ghrelin in the regulation of food intake and body weight in humans: a review. Obes. Rev. 8, 21-34. doi: 10.1111/j.1467-789X.2006.00270.x

Landgraf, P., Rusu, M., Sheridan, R., Sewer, A., Iovino, N., Aravin, A., et al. (2007). A mammalian microRNA expression atlas based on small RNA library sequencing. Cell 129, 1401-1414. doi: 10.1016/j.cell.2007.04.040

Lu, J., Luan, P., Zhang, X., Xue, S., Peng, L., Mahbooband, S., et al. (2014). Gonadal transcriptomic analysis of yellow catfish (Pelteobagrus fulvidraco): identification of sex-related genes and genetic markers. Physiol. Genomics 46, 798-807. doi: 10.1152/physiolgenomics.00088.2014

Lu, J., Zheng, M., Zheng, J., Liu, J., Liu, Y., Peng, L., et al. (2015). Transcriptomic analyses reveal novel genes with sexually dimorphic expression in yellow catfish (Pelteobagrus fulvidraco) Brain. Mar. Biotechnol. 17, 613-623. doi: $10.1007 / \mathrm{s} 10126-015-9650-\mathrm{z}$ 
Ma, W., Wu, J., Zhang, J., He, Y., Gui, J., and Mei, J. (2016). Sex differences in the expression of GH/IGF axis genes underlie sexual size dimorphism in the yellow catfish (Pelteobagrus fulvidraco). Sci. China Life Sci. 59, 1-3. doi: 10.1007/s11427-015-4957-6

Mei, J., and Gui, J. F. (2015). Genetic basis and biotechnological manipulation of sexual dimorphism and sex determination in fish. Sci. China Life Sci. 58, 124-136. doi: 10.1007/s11427-014-4797-9

Mei, J., Bachoo, R., and Zhang, C. L. (2011). MicroRNA-146a inhibits glioma development by targeting Notch1. Mol. Cell Biol. 31, 3584-3592. doi: 10.1128/MCB.05821-11

Murashita, K., Uji, S., Yamamoto, T., Rønnestad, I., and Kurokawa, T. (2008). Production of recombinant leptin and its effects on food intake in rainbow trout (Oncorhynchus mykiss). Comp. Biochem. Physiol. B Biochem. Mol. Biol. 150, 377-384. doi: 10.1016/j.cbpb.2008.04.007

Nakazato, M., Murakami, N., Date, Y., Kojima, M., Matsuo, H., Kangawa, K., et al. (2001). A role for ghrelin in the central regulation of feeding. Nature 409, 194-198. doi: 10.1038/35051587

Perez-Sanchez, J., and LeBail, P. Y. (1999). Growth hormone axis as marker of nutritional status and growth performance in fish. Aquaculture 177, 117-128. doi: 10.1016/S0044-8486(99)00073-3

Reinecke, M. (2006). "Insulin-like growth factor I and II in fish," in Fish Endocrinology, eds M. Reinecke, G. Zaccone, and B. G. Kapoor (Enfield, NH: Science Publishers), 87-130.

Salem, M., Xiao, C., Womack, J., Rexroad, C. E., and Yao, J. (2010). A microRNA repertoire for functional genome research in rainbow trout (oncorhynchus mykiss). Mar. Biotechnol. 12, 410-429. doi: 10.1007/s10126-009-9232-z

Sandoval, D. A., and Davis, S. N. (2003). Leptin: metabolic control and regulation. J. Diab. Complic. 17, 108-113. doi: 10.1016/S1056-8727(02)00167-8

Shen, Z. G., Fan, Q. X., Yang, W., Zhang, Y. L., and Wang, H. P. (2015). Effects of $17 \alpha$-methyltestosterone and aromatase inhibitor letrozole on sex reversal, gonadal structure, and growth in yellow catfish Pelteobagrus fulvidraco. Biol. Bull. 228:108. doi: 10.1086/BBLv228n2p108

Sinha, P., Singh, V. K., Suryanarayana, V., Krishnamurthy, L., Saxena, R. K., and Varshney, R. K. (2015). Evaluation and validation of housekeeping genes as reference for gene expression studies in pigeonpea (Cajanus cajan) under drought stress conditions. PLoS ONE 10:e122847. doi: 10.1371/journal.pone.0122847

Tinoco, A. B., Nisembaum, L. G., Isorna, E., Delgado, M. J., and Pedro, N. D. (2012). Leptins and leptin receptor expression in the goldfish (Carassius auratus). regulation by food intake and fasting/overfeeding conditions. Peptides 34:329. doi: 10.1016/j.peptides.2012.02.001

Trombley, S., Maugars, G., Kling, P., Björnsson, B. T., and Schmitz, M. (2012). Effects of long-term restricted feeding on plasma leptin, hepatic leptin expression and leptin receptor expression in juvenile Atlantic salmon (Salmo salar L.). Gen. Comp. Endocrinol. 175, 92-99. doi: 10.1016/j.ygcen.2011.10.001
Trümbach, D., and Prakash, N. (2015). The conserved miR-8/miR-200 microRNA family and their role in invertebrate and vertebrate neurogenesis. Cell Tissue Res. 359, 161-177. doi: 10.1007/s00441-014-1911-z

Tschöp, M., Smiley, D. L., and Heiman, M. L. (2000). Ghrelin induces adiposity in rodents. Nature 407, 908-913. doi: 10.1038/35038090

Volkoff, H., Eykelbosh, A. J., and Peter, R. E. (2003). Role of leptin in the control of feeding of goldfish Carassius auratus: interactions with cholecystokinin, neuropeptide $\mathrm{Y}$ and orexin A, and modulation by fasting. Brain Res. 972, 90-109. doi: 10.1016/S0006-8993(03)02507-1

Weil, C., Le Bail, P. Y., Sabin, N., and Gac, F. (2003). In vitro action of leptin on fsh and $\mathrm{lh}$ production in rainbow trout (Onchorynchus mykiss) at different stages of the sexual cycle. Gen. Comp. Endocrinol. 130, 2-12. doi: 10.1016/S0016-6480(02)00504-X

Williams, T. M., and Carroll, S. B. (2009). Genetic and molecular insights into the development and evolution of sexual dimorphism. Nat. Rev. Genet 10, 797-804. doi: $10.1038 / \operatorname{nrg} 2687$

Won, E. T., and Borski, R. J. (2013). Endocrine regulation of compensatory growth in fish. Front. Endocrinol. (Lausanne) 4:74. doi: 10.3389/fendo.2013. 00074

Won, E. T., Baltzegar, D. A., Picha, M. E., and Borski, R. J. (2012). Cloning and characterization of leptin in a Perciform fish, the striped bass (Morone saxatilis): control of feeding and regulation by nutritional state. Gen. Comp. Endocrinol. 178, 98-107. doi: 10.1016/j.ygcen.2012.04.019

Won, E. T., Douros, J. D., Hurt, D. A., and Borski, R. J. (2016). Leptin stimulates hepatic growth hormone receptor and insulin-like growth factor gene expression in a teleost fish, the hybrid striped bass. Gen. Comp. Endocrinol. 229:84. doi: 10.1016/j.ygcen.2016.02.003

Wu, J., Xiong, S., Jing, J., Chen, X., Wang, W., and Gui, J. F. (2015). Comparative transcriptome analysis of differentially expressed genes and signaling pathways between $\mathrm{xy}$ and yy testis in yellow catfish. PLoS ONE 10:e0134626. doi: 10.1371/journal.pone.0134626

Zhang, J., Ma, W., He, Y., Wu, J., Dawar, F. U., Ren, F., et al. (2016). Sex biased expression of ghrelin and GHSR associated with sexual size dimorphism in yellow catfish. Gene 578:169. doi: 10.1016/j.gene.2015.12.017

Conflict of Interest Statement: The authors declare that the research was conducted in the absence of any commercial or financial relationships that could be construed as a potential conflict of interest.

Copyright (c) 2017 Zhang, Ma, He, Dawar, Xiong and Mei. This is an open-access article distributed under the terms of the Creative Commons Attribution License (CC $B Y)$. The use, distribution or reproduction in other forums is permitted, provided the original author(s) or licensor are credited and that the original publication in this journal is cited, in accordance with accepted academic practice. No use, distribution or reproduction is permitted which does not comply with these terms. 